\title{
Statistical Based Real-Time Selective Herbicide Weed Classifier
}

\author{
Irshad Ahmad ${ }^{1}$ and Abdul Muhamin Naeem² \\ ${ }^{1}$ College of Computer and Information Sciences, Al Jouf University \\ ${ }^{2}$ NetSol Technologies \\ 1Saudi Arabia \\ 2Pakistan
}

\section{Introduction}

Weeds are "Any plant growing in the wrong place at the wrong time and doing more harm than good". Weeds compete with the crop for water, light, nutrients and space, and therefore reduce crop yields and also affect the efficient use of machinery. A lot of methods are used for weed control. Mechanical cultivation is commonly practiced in many vegetable crops to remove weeds, aerate soil, and improve irrigation efficiency, but this technique cannot selectively remove weeds from the field. The most popular used method for weed control is to use agricultural chemicals (herbicides and fertilizer products). In fact, the success of agriculture is attributable to the effective used of chemicals.

\section{Weed control}

Weed control is a critical farm operation and can significantly affect crop yield. Herbicides have vital importance in weed control and high crop yield however these have potential to produce harmful effects [1]. Herbicides are applied to whole field uniformly without considering the weed density. Weeds are often patchy rather than even or randomly distributed in the crop fields [2]. Total variable costs in 2002 for U.K were within a range of $£ 1,720$ / ha and $£ 1,870$ / ha for main crop potatoes, of which herbicides accounted for between $3 \%$ and $4 \%$ of costs, fungicides accounted for about $8 \%$ of variable costs and nematicides accounted for about $14 \%-16 \%$ of variable costs. United States farmers applied about $\$ 16$ billion of herbicides in 2005 (The Value of Herbicides in U.S. Crop Production: 2005 Update, Crop Life Foundation), in 1965 pesticide use was \$474.1 million for the United States. By 1970 the use of pesticides doubled to $\$ 960$ million for the United States and between 1975 and 1999 pesticide use grew 383\% for the United States (Agribusiness and Applied Economics Report No. 456), representing a significant portion of the variable costs of agricultural production. Obviously, if a more sophisticated chemical delivery system is develop which applied chemicals where weeds existed and abstained where there are no weeds, chemical usage would be reduced and chemicals would be more effectively placed. These practices would result in lower environmental loading and increased profitability in the agricultural production sector. Selectively spraying, spot spraying, or intermittent spraying are different names which are attached to this herbicide application method. 


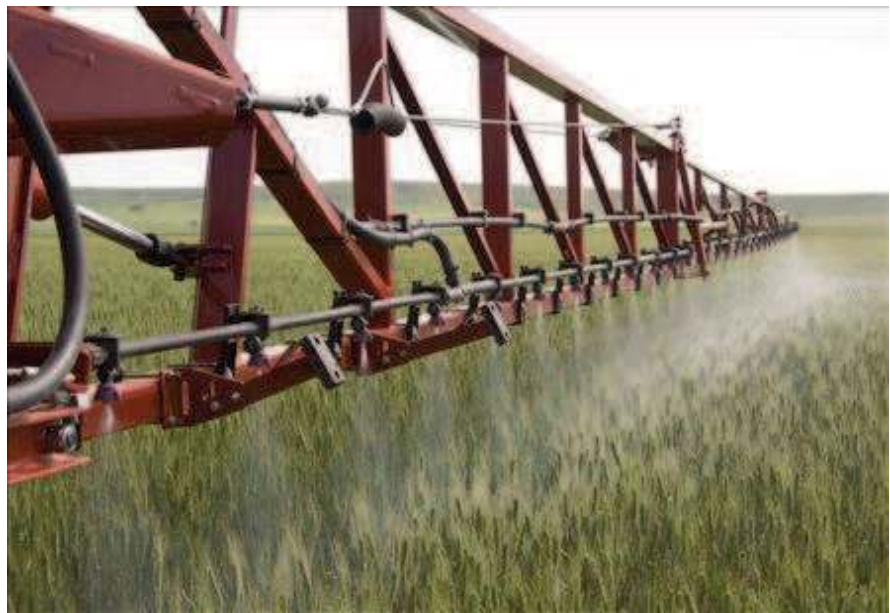

(a)

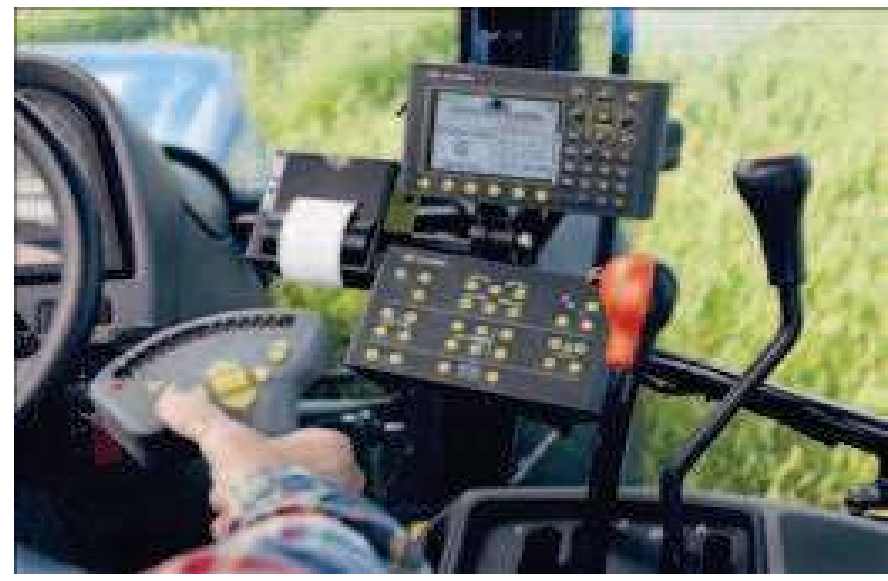

(b)

Fig. 1. (a) Automated Weed Sprayer Arm (b) Control Panel

(images are courtesy of HARDI Australia Pty Ltd)

The amount of herbicides in a control patch sprayer has been potentially reduced when realtime weed sensing is used. Patch spraying using remote sensing and machine vision are successful systems [3].

Weed Features: A verity of visual characteristics that have been used in plant identification can be divided into three categories: Spectral Reflectance, Morphology and texture.

The photosensor-based plant detection systems [4], [5] can detect all the green plants and spray only the plants. A machine-vision guided precision band sprayer for small-plant foliar spraying [6] demonstrated a target deposition efficiency of 2.6 to 3.6 times that of a conventional sprayer, and the non-target deposition was reduced by $72 \%$ to $99 \%$.

Certain accurate methods for weed detection have been developed, which included wavelet transformation to discriminate between crop and weed in perspective agronomic images [7] 
and spectral reflectance of plants with artificial neural networks [8]. Other researchers have investigated texture features [7] or biological morphology such as leaf shape recognition [6]. So in real time for the identification and classification of crop rows in images, a lot of fast methods have been implemented [9]; some of them are based on Hough transform [10], Fourier transform [13], Kalman filtering [11] and linear regression [12]. Consequently, there are various vision systems available on autonomous weed control robots for mechanical weed removal.

\section{Statistical weed classifier}

Statistical classification is a supervised machine learning procedure in which entities are placed into cluster based on quantitative information on one or more characteristics inherent in the items and based on a training set of previously labeled items.

Figure. 2 shows the Flow Chart of a Real-Time Specific Weed Recognition System which were developed to accomplish the broad and narrow weed classification. The algorithm was based on a variance of an image taken from the grayscale image which is obtained from the color image after pre-processing to detect the target area in the fields.

\section{a. Image Pre-processing}

Color images were taken from the field. Three arrays were defined to store Red, Green and Blue colors of RGB image in their respective arrays. Then the corresponding pixels from these three arrays were converted in to a single gray scale pixel using the formula

$$
\text { GrayPixel=0.299Red +0.587Green + 0.1 14Blue }
$$

The gray levels are from 0 to 255. To distinguish weeds from background objects in a grayscale image, a grayscale segmentation image-processing step is conducted where objects are classified into one of two classes (weeds and background) by their grayscale difference. Reference [14], indicated that weeds in field images must be carefully segmented; otherwise the feature extraction will yield unreliable results from analyzing soil and weeds. To identify weeds and classify them into one of two classes (broad and narrow) feature extraction are developed.

\section{b. Classification of Images using Statistical Population}

Variance and Sample Variance Statistical approach is used to describe the texture of an image. Variance is of particular importance in texture description of plants. After converting the color image into grayscale and segmentation step, the variance is then calculated. Variance for a $2 \mathrm{D}$ image from population data can be calculated as

Where

$$
\delta^{2}=\frac{\sum_{i=0}^{M} \sum_{j=0}^{N}\left(x_{i j}-\mu\right)^{2}}{M * N}
$$

$$
\mu=\frac{\sum_{i=0}^{M} \sum_{j=0}^{N} x_{i j}}{M * N}
$$


$\mathrm{M}$ represents the total number of rows and $\mathrm{N}$ represents the total number of columns in the image. Variance of a 2D image from a sample data can be calculated using a formula

$$
S^{2}=\frac{\sum_{i=0}^{m} \sum_{j=0}^{n}\left(x_{i j}-\bar{x}\right)^{2}}{m * n}
$$

Where

$$
\bar{x}=\frac{\sum_{i=0}^{m} \sum_{j=0}^{n} x_{i j}}{m * n}
$$

After calculating the variance of an image, the variance is compared with the thresholds TI and $\mathrm{T} 2$ to classify the weed into broad, narrow, and little weed as

If $\mathrm{S} 2<\mathrm{TI}$, then there is Little Weed in the processed Image

Else if $\mathrm{TI}<\mathrm{S} 2<\mathrm{T} 2$, then it is Narrow Weed

Else if $\mathrm{S} 2>\mathrm{T} 2$, then it is Broad weed

$\mathrm{TI}$ and $\mathrm{T} 2$ are set after a series of experiments done on the images.

Figure. 3 show the classification images of broad and narrow weeds, which are taken in the field. These images are processed by using Statistical Population Variance and Sample Variance of an image. The algorithm gave 100\% accuracy to detect the presence or absence of weed cover.

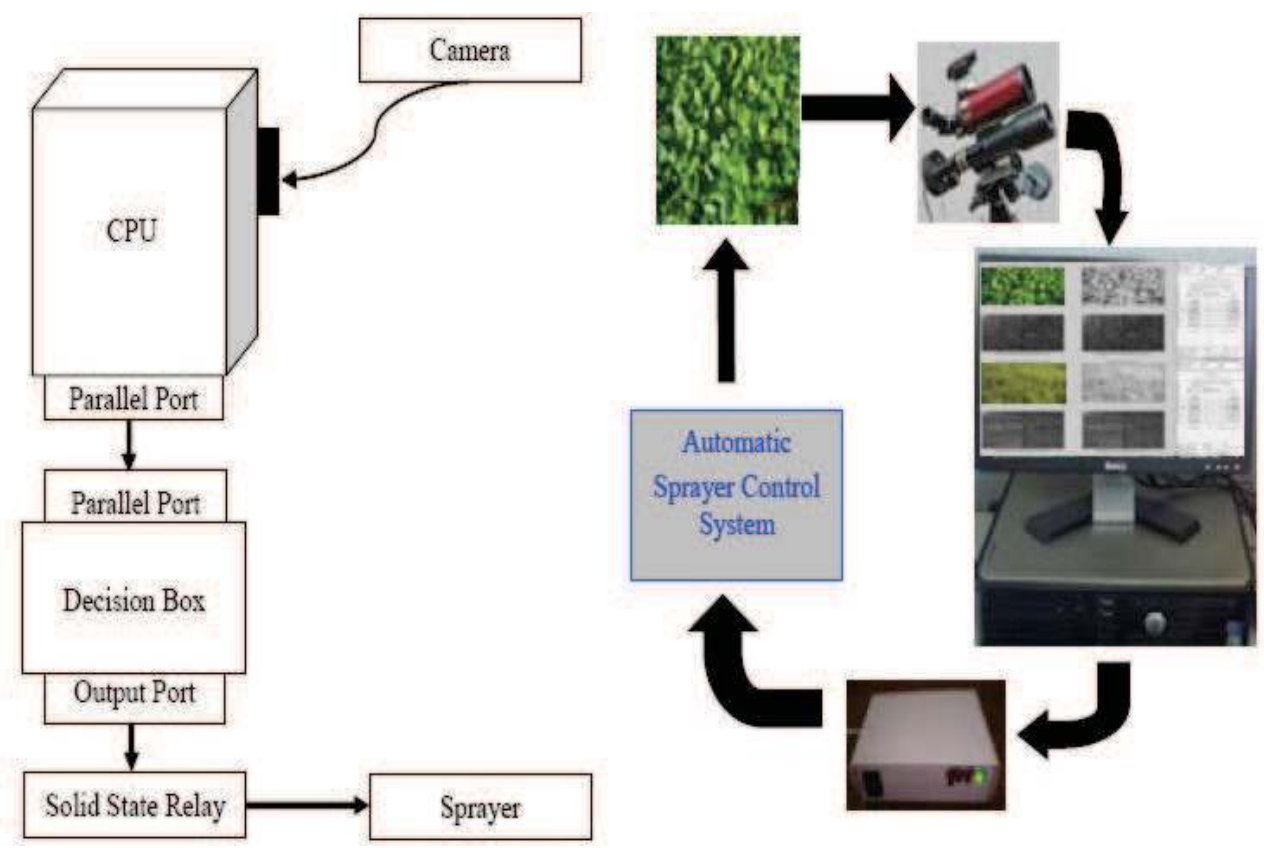

Fig. 2. Flow Chart of Sprayer System 
For areas where weeds are detected, results show 98 percent classification accuracy over 140 sample images with 70 samples from each class as shown in Table 1. The population variance and the sample variance of an image are calculated. Different samples were taken.

\begin{tabular}{|c|c|c|c|c|}
\hline \multirow{2}{*}{$\begin{array}{c}\text { Rando } \\
\text { m Samples } \\
\text { of } \\
\begin{array}{c}\text { Intensities } \\
\text { taken } \\
\text { per image }\end{array}\end{array}$} & \multicolumn{3}{|c|}{ Results found correct \% } & \multirow{2}{*}{$\begin{array}{c}\text { Time } \\
\text { for } \\
\text { Calculating } \\
\text { Variance/I } \\
\text { mage } \\
\text { (millisec } \\
\text { ond) }\end{array}$} \\
\hline Population & Narrow & $\begin{array}{c}\text { Little } \\
\text { Weed }\end{array}$ & 20 \\
\hline$(76800)$ & $98 \%$ & $98 \%$ & $100 \%$ & \\
\hline 4800 & $97 \%$ & $98 \%$ & $100 \%$ & 2.5 \\
\hline 1200 & $96 \%$ & $98 \%$ & $100 \%$ & 0.625 \\
\hline 300 & $96 \%$ & $98 \%$ & $100 \%$ & 0.3125 \\
\hline
\end{tabular}

Table 1. Results of the weeds in fig 3 using population variance and sample variance for different samples

The time taken for calculating Population Variance and Sample Variance is given in Table 1. Sample Variance is calculated much faster than Population Variance while retaining the same accuracy for weed detection. The result of taking the

Population and Samples were found the same. Less number of samples is good for high processing speed in real time environment.

\section{References}

[1] Sunil, K.M., P.R. Weckler and R.K. Taylor, 2007. Effective Spatial Resolution for Weed Detection. 2007 ASABE Annual International Meeting Sponsored by ASABE Minneapolis Convention Center Minneapolis, Minnesota 17 - 20 June, 2007.

[2] Wane N, Zhang. E.F, Sun Y. and D.E. Peterson, 2001, "Design of an Optical weed ditreibution for improved post emergence control decision", Weed Science, 40,546553.

[3] Siddiqi, M.H., S.B.T. Sulaiman, I. Faye and I. Ahmad, A Real Time Specific Weed Discrimination System Using Multi-Level Wavelet Decomposition, Int. J. Agric. Biol., Vol. 11, No. 5, 2009

[4] Shearer, S. A. and P. T. Jones. 1991. Selective application of post-emergence herbicides using photoelectrics. Transactions of the Transactions of American Society of Association Executives 34(4):1661-1666.

[5] J. E.Hanks 1996. Smart sprayer selects weeds for elimination. Agricultural Research. 44(4): 15. [4] Giles, D. K. and D. C. Slaughter. 1997. Precision band sprayer with machine-vision guidance and adjustable yaw nozzles. Transactions of the American Society of Association Executives 40(1):29-36.

[6] Manh, A.G., G. Rabatel, L. Assemat and M.J. Aldon, 2001. Weed leaf image segmentation by deformable templates. J. Agric. Eng. Res.,80: 139-146 
[7] Meyer, G., T. Metha, M. Kocher, D. Mortensen and A. Samal, 1998. Textural imaging and discriminate analysis for distinguishing weeds for spot spraying. Trans. ASAE, 41: 1189-1197

[8] Fontaine, V. and T.G. Crowe, 2006. Development of line-detection algorithms for local positioning in densely seeded crops. Canadian Biosyst. Eng., 48: 19-29

[9] Moshou, D., E. Vrindts, D.B. Ketelaere, D.J. Baerdemaeker and H. Ramon, 2001. A neural network based plant classifier. Comput. Electron. Agric., 31: 5-16.

[10] Leemans, V. and M.F. Destain, 2006. Application of the Hough Transform for seed row location using machine vision. Biosyst. Eng., 94: 325- 336

[11] Hague, T. and N.D. Tillet, 2001. A band pass filter-based approach to crop row location and tracking. Mechatronics, 11: 1-12

[12] Sogaard, H.T. and H.J. Olsen, 2003. Determination of crop rows by image analysis without segmentation. Comput. Electron. Agric., 38: 141-158

[13] Vioix, J.B., J.P. Douzals, F. Truchetet, L. Assemat and J.P. Guillemin, 2002. Spatial and spectral method for weeds detection and localization. EURASIP JASP, 7: 679-685

[14] D. M. Woebbecke, G. E. Meyer, K. Von Bargen and D. A. Mortensen, "Shape features for identifying weeds using image analysis," Transactions of the ASAE, vol. 38, no.1, pp. 271-281, 1995. 


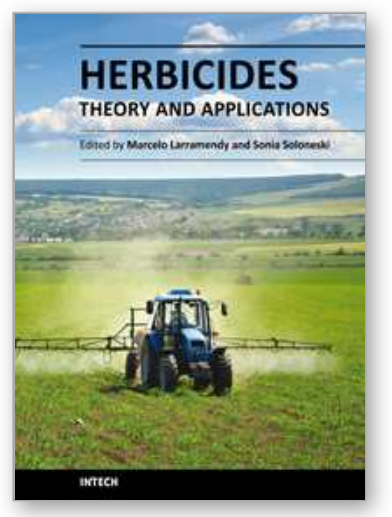

\author{
Herbicides, Theory and Applications \\ Edited by Prof. Marcelo Larramendy
}

ISBN 978-953-307-975-2

Hard cover, 610 pages

Publisher InTech

Published online 08, January, 2011

Published in print edition January, 2011

The content selected in Herbicides, Theory and Applications is intended to provide researchers, producers and consumers of herbicides an overview of the latest scientific achievements. Although we are dealing with many diverse and different topics, we have tried to compile this "raw material" into three major sections in search of clarity and order - Weed Control and Crop Management, Analytical Techniques of Herbicide Detection and Herbicide Toxicity and Further Applications. The editors hope that this book will continue to meet the expectations and needs of all interested in the methodology of use of herbicides, weed control as well as problems related to its use, abuse and misuse.

\title{
How to reference
}

In order to correctly reference this scholarly work, feel free to copy and paste the following:

Irshad Ahmad and Abdul Muhamin Naeem (2011). Statistical Based Real-Time Selective Herbicide Weed Classifier, Herbicides, Theory and Applications, Prof. Marcelo Larramendy (Ed.), ISBN: 978-953-307-975-2, InTech, Available from: http://www.intechopen.com/books/herbicides-theory-and-applications/statistical-basedreal-time-selective-herbicide-weed-classifier

\section{INTECH}

open science | open minds

\section{InTech Europe}

University Campus STeP Ri

Slavka Krautzeka 83/A

51000 Rijeka, Croatia

Phone: +385 (51) 770447

Fax: +385 (51) 686166

www.intechopen.com

\section{InTech China}

Unit 405, Office Block, Hotel Equatorial Shanghai

No.65, Yan An Road (West), Shanghai, 200040, China

中国上海市延安西路65号上海国际贵都大饭店办公楼 405 单元

Phone: +86-21-62489820

Fax: $+86-21-62489821$ 
(C) 2011 The Author(s). Licensee IntechOpen. This chapter is distributed under the terms of the Creative Commons Attribution-NonCommercialShareAlike-3.0 License, which permits use, distribution and reproduction for non-commercial purposes, provided the original is properly cited and derivative works building on this content are distributed under the same license. 